\title{
O Paradoxo dos Centros Históricos - O Caso de Florianópolis
}

\author{
Alicia Norma Gonzalez de Castells
}

Universidade Federal de Santa Catarina, Florianópolis, Santa Catarina, Brasil E-mail: alicianormacastells@gmail.com 


\section{Resumo}

Nesta reflexão pretende-se discutir o lugar do patrimônio cultural em centros históricos a partir da consideração do patrimônio como uma categoria de natureza processual. À luz das práticas do cotidiano, problematizar os níveis de ressonância dos bens escolhidos e legitimados pelo Estado. Trazer à tona os meandros das revitalizações ou das reabilitações urbanas sob a ótica do valor patrimonial que eles possuem. Por fim, focando em particular no Centro Histórico de Florianópolis (Brasil), o objetivo prioritário é dar visibilidade às tensões e aos conflitos do campo patrimonial entre o valor de troca e o valor de uso do patrimônio urbano.

Palavras-chave: Patrimônio Cultural. Centros Históricos. Práticas do Cotidiano. Revitalizações Urbanas.

\section{Abstract}

This paper intends to discuss the place of cultural heritage in urban centers from the perspective of heritage as a procedural nature category. In the face of day-to-day practices it aims to question the impacts of state selected and legitimated estates, and shed a light on urban regeneration intricacies from a heritage interest standpoint. Focusing particularly on the Florianópolis Historic District, its main objective is to highlight tensions and conflicts within the heritage sphere that examine urban heritage usevalue vs. exchange-value.

Keywords: Cultural Heritage. Urban Centers. Day-to-day Practices. Urban Regeneration. Urban Renewal. 


\section{Introdução}

— studar os centros históricos na nossa contemporaneidade permite elucidar o que considero um paradoxo: neles se revela tanto o passado como o presente. O novo e o velho. O uso de novas tecnologias destoando com paisagens tradicionais. Intervenções urbanas remoçando paisagens antigas em luta pela continuidade de tempos idos. Intervenções que exigem, por sua vez, políticas higienizadoras do espaço urbano. Medidas que descartem a sujeira e a desordem da vida social; que removam, em certo tempo, os persistentes e/ou retardatários desses lugares, pensados alhures como públicos. Transformações da paisagem socioespacial sob o efeito de cirurgias estéticas resultado de revitalizações, qualificações, enobrecimentos (entre alguns dos termos criados pela família das gentrificações urbanas $)^{1}$ capazes de produzir cenários assépticos e embelezamentos paisagísticos para a vinda do turismo cultural e/ou usuários locais gabaritados socialmente.

Pensados como peças patrimoniais, o que se valoriza em geral desses centros históricos é o que eles expressam em relação a períodos históricos passados reunindo estilos arquitetônicos de época-museus a céu aberto expondo tanto seu valor estético como a memória das forças econômicas políticas que os erigiram e lhes deram sentido. Tramas urbanas - ruas, praças, monumentos, construções - que foram testemunho das vivências de seus infinitos usuários. Paisagens culturais feitas e refeitas no caldeirão das políticas das diferentes esferas nacional, estadual e municipal.

Como testemunho dessa riqueza patrimonial que guardam cidades, bairros e centros históricos, o Conselho Internacional dos Monumentos e dos Sítios (ICOMOS) redigiu a Carta Internacional para a Salvaguarda 
das Cidades Históricas, a Carta de Washington (1987), que especifica, entre outras considerações, que os valores a ser preservados são o caráter histórico da cidade e o conjunto de elementos materiais e espirituais que lhes determinam a imagem. Sobre essas recomendações, referente ao patrimônio cultural, cobiçadas desde a esfera internacional que vinculam de forma harmoniosa os elementos materiais e espirituais na salvaguarda da imagem das cidades históricas, cabe perguntar, entretanto, se essas recomendações fazem sentido nas esferas nacional e local. Os exemplos das cidades históricas de Colonial Williamsburg, nos Estados Unidos, e Ouro Preto, no Brasil, analisadas por Gonçalves $(2007)^{2}$ e Lima Filho (2006) são um testemunho revelador das visões diferenciadas em escalas nacionais de concepção, percepção e práticas de preservação do patrimonial.

\section{Materialidade e Imaterialidade dos Centros Históricos}

Nesta reflexão interessa-nos salientar os casos das cidades e centros históricos que, embora sujeitos a critérios de preservação de organismos e agentes patrimoniais, interagem com as dinâmicas urbanas. De como suas materialidades, como bens patrimoniais são (des)contextualizados e (re)contextualizados sob o agir dessas dinâmicas sociais. Em relação a esse movimento de (des) e (re) contextualização dos bens patrimoniais no espaço público, a discussão de Canclini (2005) sobre a dinâmica contemporânea do urbano é ilustrativa. Questionando-se sobre o perigo de aceitar uma perspectiva linear da história, no caso hipotético de considerar "[...] as tecnologias comunicativas [como substitutivas], a herança do passado e a interação pública". Propõe-se a analisar o que ele caracteriza como usos modernos e pós-modernos da história. Focando no lugar que ocupam hoje os monumentos sob a força das transformações das cidades, se comparados com “[...] fenômenos transitórios como a publicidade, o grafite e as manifestações políticas [...]" (Canclini, 2005, p. 265), Canclini defende que a vida urbana transgride as ordens estabelecidas e nela se cruzam interesses tanto históricos, estéticos como comunicacionais. Nessa perspectiva, sustenta que os bens patrimoniais, os monumentos e os museus, nestes últimos, 
os objetos históricos são subtraídos à história, congelados a uma eternidade, enquanto os primeiros permanecem abertos à mudança permitindo que a memória interaja com as transformações (Canclini, 2005, p. 275).

Pode-se afirmar que a materialidade no espaço urbano é suporte de práticas, de vivências, de imaginários e, por sua vez, é suportada. Sobre os meandros desse entendimento atribuído à materialidade Gorosito Cramer (2001) postula que nos encontramos diante de uma reversão da centralidade dada historicamnete à materialidade. A partir do momento em que se evidencia um objeto patrimonial classificado como tangível, discute-se a relação entre patrimônio tangível-intangível, questionando a centralidade dada ao primeiro e a sua condição de natureza intrínseca atribuída ao patrimônio. Por outro lado, a autora aponta que a centralidade da imaterialidade do objeto material termina sendo resultado de processos de atribuição de valor, dado pelas gestões patrimoniais locais e pelas organizações internacionais (Gorosito Cramer, 2001, p. 37-43). Em todo caso, vemos que é preciso sinalizar que há divergências no que se entende por bens patrimoniais; existem ambiguidades e escalas valorativas visíveis sobre estes bens. E é preciso sinalizar que ante a presença de patrimônios legalmente reconhecidos por leis e normas, existem outros bens que, embora socialmente apropriados, não possuem o mesmo reconhecimento oficial, representando uma mostra dessa condição ambígua em atribuir valor patrimonial (Delgadillo, 2015).

Os desencontros sobre o entendimento dos bens antes apontados podem ser também analisados a partir das preocupações de Pratz (1997) sobre a natureza da categoria patrimonial. O autor argumenta que as políticas de conservação e difusão do patrimônio o concebem como uma realidade essencial preexistente, não como uma construção social. As escolhas partem desses princípios implícitos sem questionálos nem refletir sobre eles. Na sua visão, a atribuição de significado por parte da população local aos bens referenciais do patrimônio não corresponde à atribuição de valor e ativação por parte dos poderes locais. Existem diferentes e contraditórios tempos entre “[...] a lógica do mercado, em curto prazo, e as necessidades reais ou percebidas 
como tais, que não necessariamente devem ajustar-se aos tempos políticos" (Pratz, 1997 apud Castells, 2012, p. 27). Nesse mesmo viés, Gonçalves (2005) sustenta que a falta de reconhecimento esperado junto aos setores da população revelaria que o patrimônio em si não depende apenas da vontade e da decisão política de uma agência do Estado. Nem exclusivamente de uma atividade consciente e deliberada de indivíduos ou grupos. Para o autor, eles só se constituem como bem quando encontram ressonâncias junto a seu público. Esta última categoria é a que expressa o poder que possui o objeto "[...] de evocar no espectador as forças culturais complexas e dinâmicas das quais emergem e das quais, para o espectador é representante [...]" (Greenblatt, 1991, p. 42-56), citado por Gonçalves (2005, p. 19). Nessa areia movediça de dúvidas e desencontros, Arantes (2006, p. 427) sustenta que

[...] a prática da preservação não legitima simplesmente sentidos socialmente atribuídos pela cultura comum e cotidiana a determinados aspectos da cultura, mas põe em prática os critérios, as concepções e os valores que são defendidos por técnicos e especialistas (arquitetos, urbanistas, historiadores, arqueólogos, antropólogos e geógrafos, entre outros). Consequentemente as decisões das instituições de preservação podem estar em desacordo - e não raramente estão - com os valores vigentes locais.

\section{Centros Históricos sob a Lente do Cotidiano}

Sob a mira da lente do cotidiano, os centros históricos, locais perpassados num sem-fim, por frequentadores de dentro e de fora, permanentes e/ou ocasionais, outsiders e donos do pedaço, são objeto de diversas práticas e evocações sociais que vão desde apropriações territoriais delimitadoras de fronteiras simbólicas (Arantes, 2000), até a revelação de subjetividades. Sentimentos que, quando emergem, esboçam cartografias socioespaciais vividas neles.

Desse território - constituído fisicamente por ruas, praças, monumentos, materialidades muitas dessas erigidas hoje como bens patrimoniais louváveis de pertencer ao baú das memórias nacionais - interessa analisar as formas de apropriações, usos, atributos, 
suportes, desses mesmos bens materiais reconhecidos. Antes, porém, de adentrar nessas especificidades do cotidiano urbano gostaria de expor características consideradas agregadoras do patrimônio edificado, como simbolismos para as populações detentoras desses bens.

Delgadillo (2015) sustenta que muitos dos edifícios e espaços urbanos têm se construído com a ideia de congregar e manter unidos os coletivos sociais. E embora outros não tenham sido construídos com esses fins, entretanto têm desempenhado as mesmas funções. Entre as características marcantes desses edifícios e espaços urbanos, está, principalmente, a percepção de eternidade que deles se tem, por sua transcendência à vida humana. Como base nas escolhas e decisões usadas pelos grupos de poder do que se apaga, do que se preserva ou se constrói na configuração de uma história oficial. O autor alega que a cidade é a sua maneira uma memória coletiva para seus residentes, pois ela está associada aos objetos e lugares onde se habita. Nesse sentido, segundo Delgadillo, em princípio, a ética da conservação do patrimônio urbano e cultural reivindica a permanência do patrimônio edificado porque contribui para a construção da identidade coletiva baseada na originalidade e a diferença entre culturas e povos, e a assegurar uma memória social que orienta o futuro desses grupos sociais. Se bem compartilhamos a tese de Delgadillo sobre a importância dos edifícios e espaços urbanos no que tange à construção de uma memória coletiva, é preciso antes, em base aos apontamentos de Pratz, Gorosito, Arantes, Gonçalves, Castells, voltar a se questionar em relação à legitimidade dos bens patrimoniais concebidos como tais. Em última instância, esses bens seriam bens de referência para quem? (Fonseca, 2003).

\section{Centro Histórico de Florianópolis}

Nesse viés, delimitando o Centro Histórico de Florianópolis como unidade analítica, trago para discussão alguns exemplos que questionam ou dialogam com as questões anteriormente apresentadas. No entendimento, como ressalta Arantes (2006, p. 425-426) de que

[...] Sem abandonar as questões conceituais, mas também sem se satisfazer com generalizações abstratas, as contribuições mais críticas e, portanto, mais produtivas 
têm se referido a marcos espaço-temporais concretos, bem como a grupos sociais específicos.

Exemplos do cotidiano que questionam a centralidade que ocupa o bem material no campo patrimonial. Que revelam o que fica oculto nas sombras em relação ao que se considera patrimônio cultural, ou, ao menos, a quem pertence esse patrimônio - formas de pertencimento ou exclusão de temporalidades vividas que podem ser lidas por meio de diversas marcas alegóricas contidas nesse centro. Por outro lado, exemplos que mostram a tensão dessas marcas e identidades coletivas sob o impacto das intervenções urbanas.

\subsection{Museu Histórico de Santa Catarina. Marcas de exclusão}

Entre os bens materiais reconhecidos do patrimônio cultural do Centro Histórico de Florianópolis, o Palácio Cruz e Sousa é reconhecido como tal. Construído em meados do século XVIII, na frente da Praça XV de Novembro, serviu como residência e sede de governo até 1986, sediando a partir desse ano o Museu Histórico de Santa Catarina (MHSC). Dessa construção tombada pelo patrimônio histórico do Estado e pelo município, entre as características decorativas, ornamentais internas e externas do bem se destacam os ladrilhos da calçada à frente do palácio, fazendo-se referência de que estes foram importados e assentados no ano de $1910^{3}$.

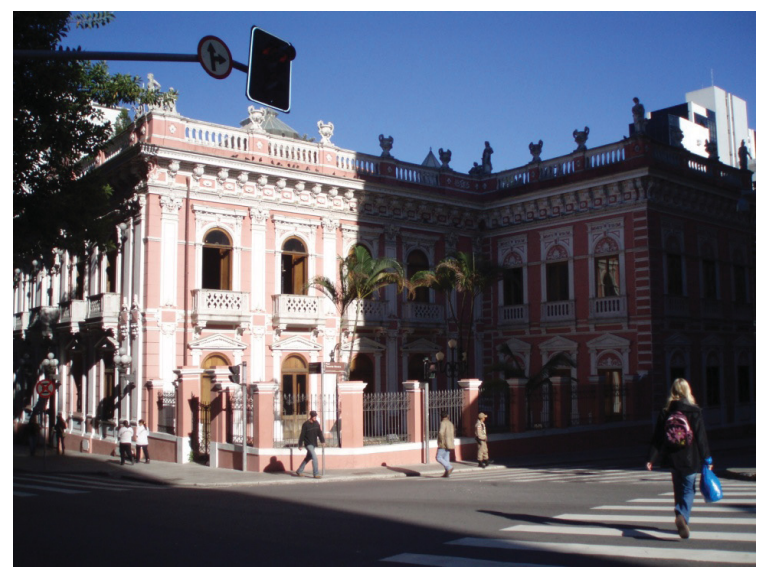

Fotografia 1: Museu Histórico de Santa Catarina Fonte: Baur (2007)

ILHA

v. 20 , n. 2, p. 27-51, dezembro de 2018 
Do cotidiano vivido, senhoras negras idosas, moradoras da comunidade do Mont Serrat, localizada no Maciço do Morro da Cruz, relatam como, na época da sua mocidade, elas não podiam transitar pelas calçadas do Palácio Cruz e Sousa, localizado na frente da Praça XV de Novembro. As calçadas, em princípio área de trânsito livre do espaço público, no caso do Palácio Cruz e Sousa, não eram lugar de negros. Já essas mesmas calçadas e as perimetrais da Praça XV, assim como em outras cidades da época, eram o passeio dominical obrigatório das moças casamenteiras da sociedade local que habitavam inclusive no entorno do passeio.

Os ladrilhos da calçada hoje rememorados e pertencentes a um bem reconhecido da cidade tinham donos em épocas passadas. Nos defrontamos com bens materiais de preservação que evocam uma identidade local nacional se digladiando nas narrativas de um passado escravagista. O patrimônio cultural como espelho das diferenças. Em síntese, a preservação pertenceria "[...] a um campo de motivações e estratégias referidas a sistemas de forças sociais [...]" (Arantes, 2006, p. 426).

\subsection{Catedral Metropolitana - Disputa de Sentidos Patrimoniais}

O largo da Catedral Metropolitana de Florianópolis, na manhã de um sábado de maio de 2014, viveu um episódio digno da reflexão de Clifford (1995) na introdução de seu livro, intitulado: Os produtos puros enlouquecem. Acompanhada por um grupo de alunos da Universidade Federal de Santa Catarina (UFSC), nos concentramos na escadaria da Catedral Metropolitana, no intuito de realizar uma pesquisa de campo exploratória. Como atores situados numa tela panorâmica, desde as duas laterais da escadaria central da catedral fomos progressivamente expostos (entre sons altos, cartazes, trajes, pinturas, todo tipo de performance a céu aberto) a dois grupos de indivíduos que se organizavam para celebrar a Festa do Divino ${ }^{4}$ e realizar a Marcha das Vadias ${ }^{5}$ ao mesmo tempo. Na concentração do Divino, famílias e autoridades locais, muitos deles usando roupas rituais, se formavam para dar início à festividade, deslocando-se desde a frente da catedral para circular 
em volta da Praça XV de Novembro. Na concentração das Vadias, a maioria mulheres jovens (mas também com a presença de homens e crianças) se organizavam para uma passeata. Entre as participantes da marcha, muitas delas mostravam seus corpos seminus pintados e portavam cartazes alegóricos a suas demandas e cânticos alusivos a suas exigências. Guardas policiais postados nos arredores observavam o desenrolar dos fatos. Nós, alunos e professora, espectadores privilegiados desses acontecimentos, os percebíamos como eventos, a princípio, irreconciliáveis nesse lugar ao mesmo tempo.

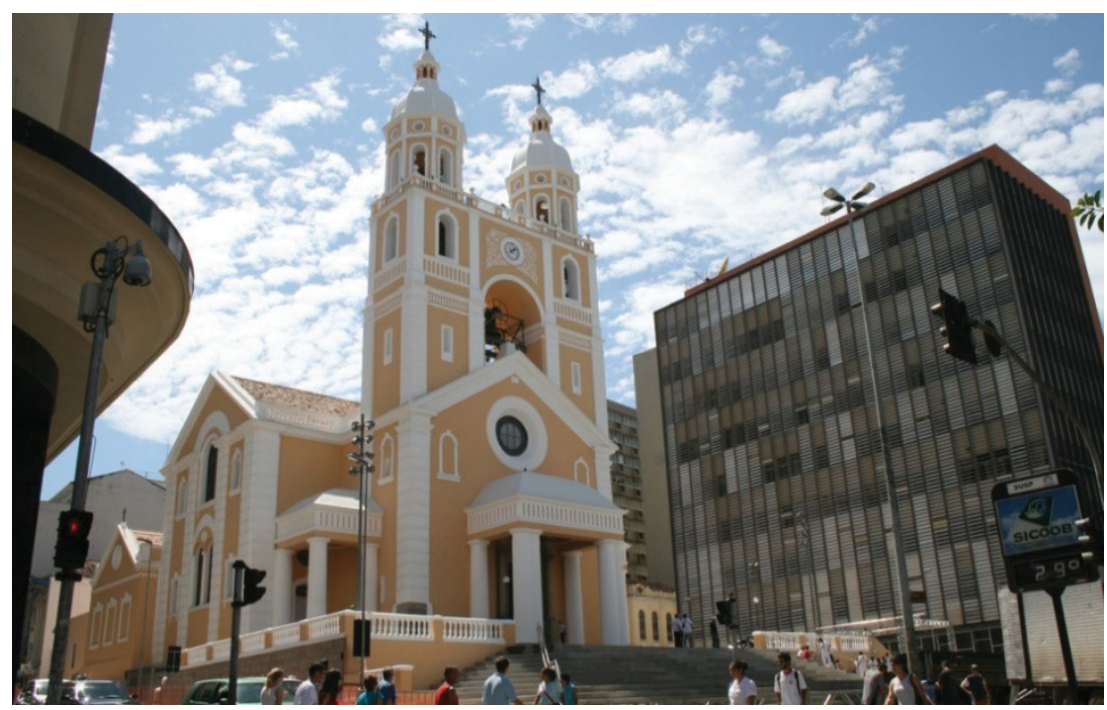

Fotografia 2: Catedral Metropolitana de Florianópolis Fonte: Ornato Arquitetura (2015)

O local escolhido por esses dois grupos foi exatamente o largo da Catedral Metropolitana. Bem patrimonial, sem dúvidas, reconhecido popularmente. Ante esse fato me perguntei e questionei meus alunos sobre o porquê dessa escolha. A princípio, da escolha feita pelo grupo do Divino, poderia se depreender que, sob a percepção de seus seguidores, o largo da Catedral era tido como lugar de tradição religiosa. Lugar de continuidade das tradições locais. Já a escolha feita pelo movimento das Vadias poderia ter respondido à identificação do sítio como lugar de alta visibilidade em termos de desafio às instituições tradicionais. Nossa observação de rua não previu fazer entrevistas, portanto, nos limitamos 
ao registro visual e sonoro dos imponderáveis desse cotidiano matinal que alimentou uma vez mais, a necessidade de distanciamento dos lugares familiares como era o caso do centro tantas vezes frequentado por muitos de nós.

Rememorando o ocorrido depois de algum tempo, agora à luz do campo patrimonial, o edifício da Catedral Metropolitana, sua escadaria, o largo e seu entorno, lugar de encontro proposital dos dois grupos, como bem material patrimonial reconhecido, foi suporte de duas práticas dissimiles e simultâneas. O bem material, se pensado em relação a cada um dos dois grupos, recebeu simbologias contraditórias entre si. Foi alvo de ressonâncias discordantes. Um evocando a ideia de lugar (Augé, 1994) como expressão de uma continuidade da tradição imolada. O outro, apropriando-se desse sentido de lugar, mas tergiversando no uso, como forma de protesto e maior visibilidade das bandeiras desse movimento social. A Catedral como bem material reconhecido foi suporte simbólico de ambos os casos. E não foi precisamente pela sua imponência ou centralidade na malha urbana, e sim sob a égide das dinâmicas urbanas de nossa contemporaneidade nos moldes que nos fala Canclini (2005) quando se refere ao lugar que ocupam os monumentos. Podendo se afirmar que os bens - portadores de selos patrimoniais, imersos nas continuidades e descontinuidades dessas dinâmicas urbanas - como bens de referência fazem parte de um mundo de distintos sistemas de significados no qual os produtos puros enlouquecem (Clifford, 1995).

\subsection{Escadaria do Rosário e Igreja de Nossa Senhora do Rosário e São Benedito - (Re)contextualizações do Patrimonial}

Na escadaria da rua Trajano, conhecida como a escadaria do Rosário, delimitada na sua margem superior pela Rua Marechal Guilherme e na inferior pela Rua Vidal Ramos, às terças-feiras pela manhã, o centro ferve e desde o dia 11 de julho de 2017 uma Feira Afro-Artesanal toma conta do lugar. O local dessa feira fica emoldurado nas alturas, pela Igreja de Nossa Senhora do Rosário e São Benedito, conhecida também como a Igreja dos Negros ${ }^{6}$. A seus pés, qual espaço 
de transição entre o sagrado e o profano, a feira deságua na rua Vidal Ramos, rua revitalizada, inaugurada em 15 de março de 2012, que se constitui, de fato, em área de fronteira simbólica com a Feira AfroArtesanal, por ser uma rua que se pretende "[...] com ares de shopping a céu aberto, mas com regras de shopping fechado" (Castells, 2014, p. 184).

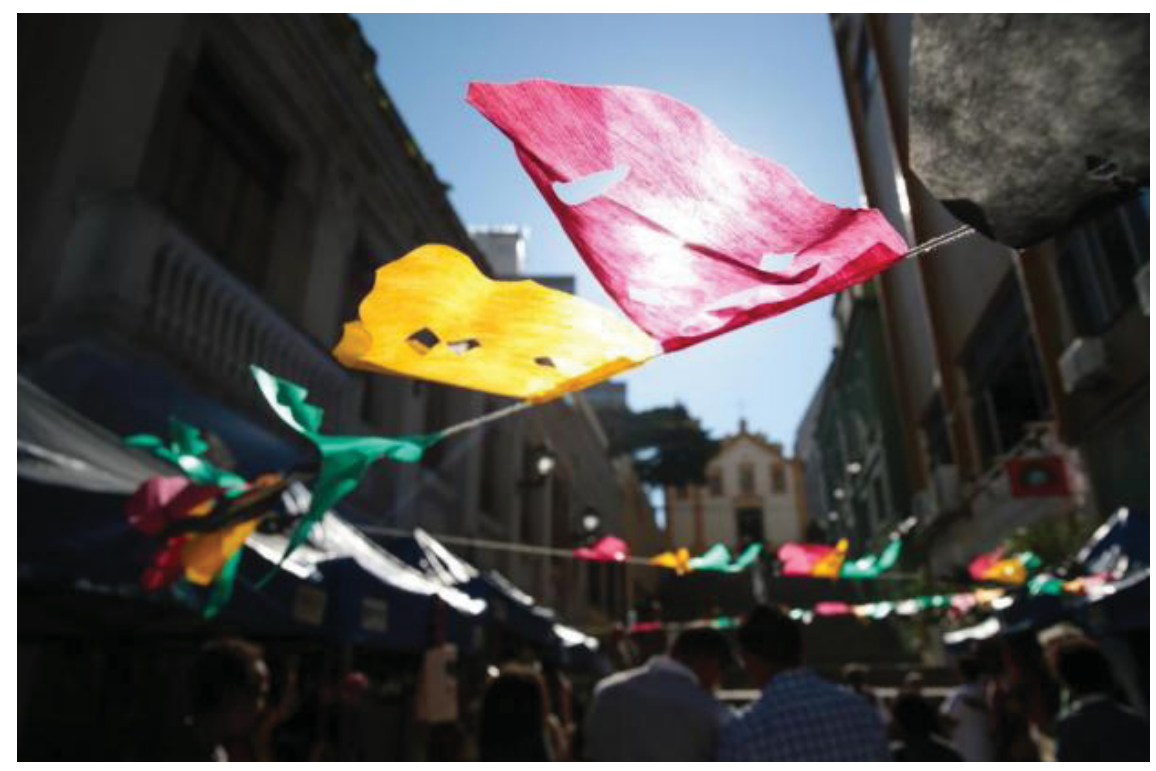

Fotografia 3: Feira Afro-Artesanal

Fonte: Cristiano Estrela (2017)

No conjunto urbano constituído pela Escadaria do Rosário, a Igreja de Nossa Senhora do Rosário e São Benedito e a Feira Afro-Artesanal - feira concebida pelos seus praticantes como "quilombo urbano" ${ }^{7 \text { " }- \text { os }}$ bens de referência materiais-imateriais se entrelaçam. A Escadaria e a Igreja, qual paisagem física unívoca da trama urbana são ressignificadas pela Feira Afro-Artesanal. Os negros ocupam a escadaria do Rosário e (re)configuram esse lugar histórico na contemporaneidade. Embora a feira não seja uma ocupação de tipo permanente, é suportada e age como suporte simbólico da Escadaria e da Igreja. Bens patrimoniais que, como vimos pela sua história e antiguidade, fazem parte dessa paisagem da trama urbana há tempos consolidada.

Constata-se que já não são somente reminiscências de camadas arqueológicas de tempos idos que configuram e modelam a paisagem 
tradicional histórico-cultural desse centro. Dessas antigas paisagens emergem outras paisagens, que ocupam e disputam o pretendido espaço público. Mas, se por um lado, o passado de lugares negros esquecidos é ressignificado no presente, atribuindo-lhe novos sentidos aos lugares que compõem a trama urbana; por outro, a essa mesma trama urbana lhe é atribuída também a lei do fenômeno das novas intervenções urbanas, agrupadas, muitas delas, sob a égide das gentrificações. Assim, nos encontramos com uma simultaneidade de ações, práticas e intervenções que disputam entre si os sentidos atribuídos temporal e espacialmente a esses mesmos bens patrimoniais. Evidenciando, mais uma vez, a natureza da categoria patrimonial como uma categoria processual.

\subsection{Trama Urbana do Centro Histórico de Florianópolis}

Parode (2018), focando na sociabilidade de outros atores desse mesmo Centro, fundamentalmente, a dos(as) indígenas que vendem artesanato no local, observa que nessa prática o espaço urbano, o lugar construído, "[...] adquire uma nova função e um novo modo de uso" (Parode, 2018, p. 66). Como se pode apreciar em suas palavras,

[...] Diante das primeiras observações, notei que algumas das mulheres guarani que vendem o artesanato como uma prática cotidiana, sobre os panos, quase que diariamente. Subvertem ao estigma do chão, que na cidade é visto como não digno utilizado por pessoas em situação de vulnerabilidade social, ou mendicância [...]. (Parode, 2018, p. 66)

Valendo-se do conceito de apropriação de Schneider (2003), Parode (2018, p. 66) argumenta que a presença dos indígenas no centro de Florianópolis para venda de seu artesanato, prática que exige a ocupação do espaço público, representa uma reelaboração de mundo na ocupação e posse da trama urbana. A seguir, faço referência a outros exemplos, especificamente, aquelas intervenções urbanas que mudaram e mudam a imagem do centro histórico florianopolitano. 


\subsection{Aterro da Baia Sul - Alegorias de uma Paisagem Marítima}

Em termos físicos, a continuidade do tecido urbano no perímetro do centro histórico é uma constante que remete a um tempo passado, preservando essa história local. Ruas, largos, servidões, a Praça XV que sofreram transformações em diversos períodos, como aponta Coradine (1995). Passou de espaço militar e portuário, higienizado, modernizador, carnavalesco e, ainda hoje, continua a ser um dos espaços centralizadores de atividades da trama urbana do centro histórico de Florianópolis. Entretanto, a construção do aterro da Baía Sul, entre 1972 e 1978, foi uma ruptura entre terra e mar dessa mesma trama. Um rasgamento do tecido urbano. Uma perda da imagem tradicional da cidade como ilha banhada por mar. Paisagem marítima depois evocada por monumentos como é, por exemplo, o memorial ao Miramar pórtico alegórico do antigo contato entre o mar e a terra, hoje desaparecido pela construção do aterro $^{8}$.

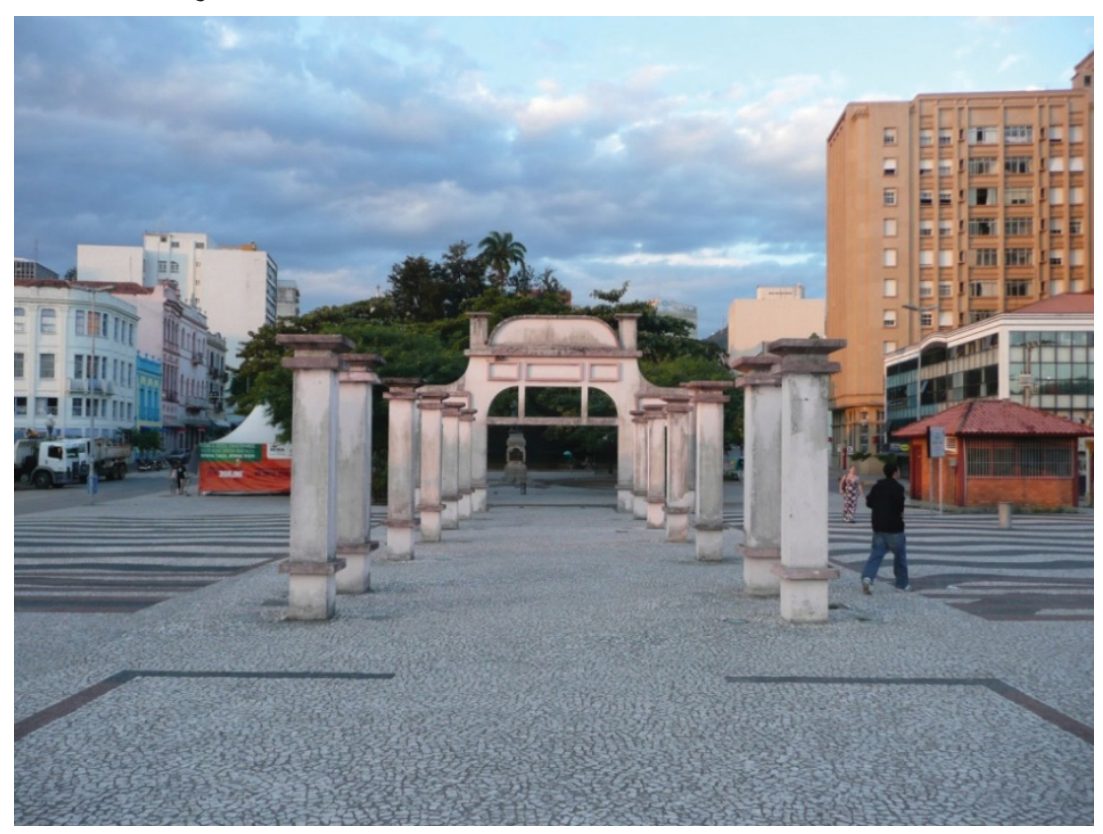

Fotografia 4: Pórtico do Miramar Florianópolis

Fonte: Petroski (2018) 
Pois bem, constatamos, assim, que a paisagem do centro histórico - sem esquecer que a noção de paisagem é construída socialmente deixou de ser marítima pela construção de um aterro que expressava o progresso: a construção de estradas em todo território nacional. E a paisagem de beira mar se transformou numa avenida de alta velocidade, edifícios dando as costas ao mar, tapume visual entre o Centro Histórico e o mar. Essa intervenção, porém, impediu, de forma dramática, os florianopolitanos de manter o contato com o mar desde esse centro histórico e negou também a continuidade de uma imagem de cidade fincada na beira do mar, excluindo parte de sua originalidade. Já outras intervenções aparentemente menos dramáticas realizadas dentro da poligonal urbana qualificada apresentam um caráter mais sutil, mas são também suspeitas de poder acabar com as originalidades locais?

\subsection{Mercado Público de Florianópolis}

Entre as intervenções realizadas dentro dessa Área de Preservação Cultural, o Mercado Público foi um desses alvos pela via de concurso público nacional de ideias.

O Instituto de Arquitetos do Brasil Departamento de Santa Catarina (IAB) lançou o edital do concurso nacional para o vão central do Mercado Público de Florianópolis, cujo objetivo [era] a construção de uma cobertura para o vão do emblemático edifício que faz parte da memória urbana e desempenha, hoje, um papel essencial para a dinâmica do centro da capital catarinense. O vão do edifício, hoje descoberto, propicia uma infinidade de trocas e relações entre as pessoas que passam ou permanecem no centro da cidade. Segundo o edital "a principal premissa é que o projeto interfira o mínimo possível no patrimônio tombado, com preferência por uma cobertura translúcida e retrátil". (Baratto, 2013)

Em novembro de 2013, o escritório de arquitetura Aleph Zero foi o vencedor. Em matéria publicada pelo site de projetos de arquitetura, ArchDaily (2013), os ganhadores destacam que para a criação da nova cobertura mantiveram presentes a história, os usuários e a vida local do lugar. Como eles sintetizam a seguir: 
[...] uma multiplicidade de tempos concomitantes, pautados nos últimos 160 anos pela afluência de usuários ao Mercado Público cuja história inclui demolições, mudanças de local, renovações diversas, e a participação ativa de gerações de consumidores, vendedores e administradores. (Baratto, 2013)

E nesses termos, argumentam que

[...] a nova cobertura para o vão central configura-se, então, como mais um elemento nessa narrativa, e como tal deve respeitar e adicionar ao existente sem tornar-se irrelevante ou caracterizar-se como mero fechamento. (Baratto, 2013)

\section{Ainda sustentam que}

[...] Cria-se uma nova escala, protegida dos elementos, com o intuito de suportar adequadamente novas histórias complementares: feiras temporárias, apresentações culturais, festividades, projeções, desfiles etc. (Baratto, 2013)

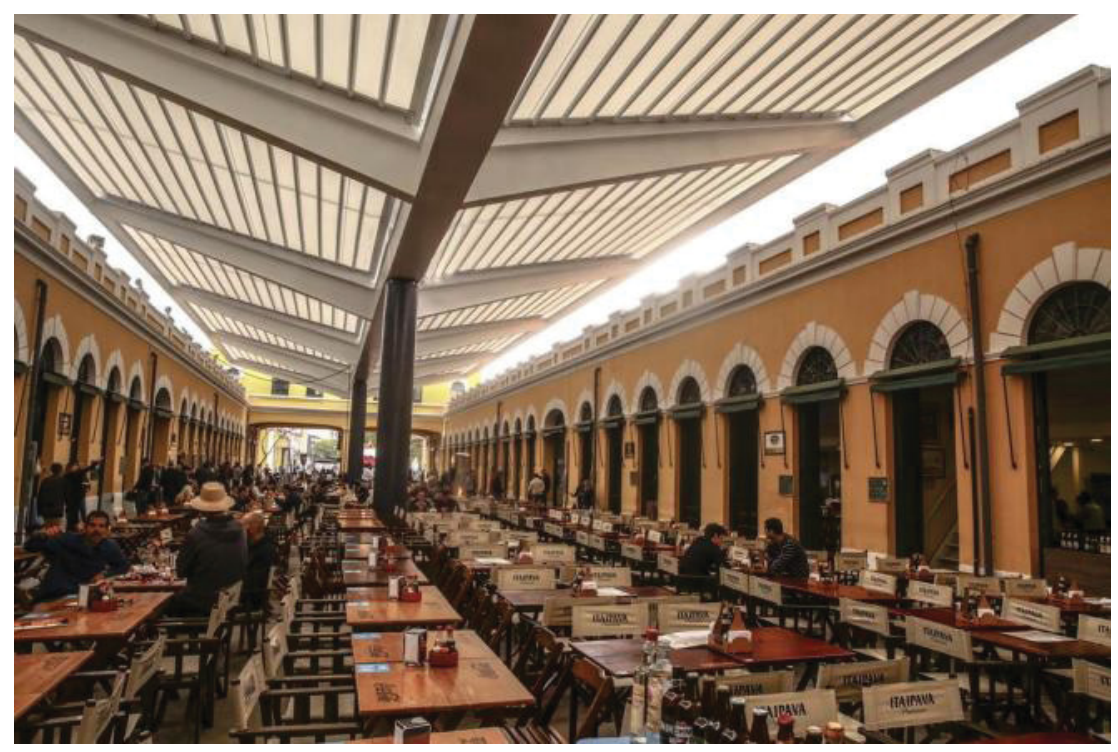

Fototografia 5: Mercado Público de Florianópolis

Fonte: Favero (2016) 
Antes de pontuar algumas observações sobre o novo cotidiano do pátio do mercado público, após intervenção da cobertura citada, vale esboçar uma sucinta problemática sobre modalidades e destinos dos mercados na nossa contemporaneidade.

Pintaudi (2006, p. 82) defende que "[...] as formas espaciais (estrutura e função incluídas) têm uma duração no tempo e o seu movimento requer permanente reinterpretação". No caso dos mercados públicos, além de sua gênese e forma espacial, se deve considerar "[...] a definição que a cada momento a sociedade lhe atribuiu". Para a autora, os mercados públicos, dentro ou fora das cidades, como forma-função, local de abastecimento e trocas de produtos necessários à reprodução da vida, nunca foram objeto de questionamentos. Mas ante a emergência de outras formas de abastecimento que redundam em potenciais transformações, se geram outras formas de apropriação, concebendoos agora como lugar "tradicional". Onde se pretende produzir uma "identidade" para a sociedade local, ou então o desaparecimento dessa forma da paisagem urbana e, consequentemente, do imaginário.

Delgadillo (2016, p. 3-4), na sua apresentação ao dossiê referente a uma farta produção sobre as tendências atuais ao redor dos mercados, frisa que o discurso da obsolescência físico-funcional e econômica conhecida como o ocaso de um "ciclo natural de vida", legitima um conjunto de políticas públicas e projetos privados que pretendem atribuir outros usos (centros culturais, comerciais ou de divertimento) ou mesmo a substituição dos mercados por edifícios de maior altura, ou mesmo transformá-los em mercados de comida gourmet ou de produtos "típicos". Como contrapartida a tendência sobre o "ocaso" dos mercados valendo-se de um dos artigos do dossiê, o de Lacarrie, referencia o caso das populações indígenas da Bolívia e do Equador que, no mercado urbano, reproduzem sua cultura e sua vida social. Para Delgadillo há uma tendência a eliminar da discussão a dimensão social dos mercados. Em síntese, o autor sustenta que a disputa por esses espaços não é meramente algo isolado, mas faz parte de uma disputa por um modelo de sociedade e de cidade, por último, de um tipo de "mercado". 
No caso do mercado de Florianópolis, antes da idealização e intervenção da cobertura do vão central, Castells (2014) se questionava sobre os critérios que estariam sendo usados para a idealização dessa cobertura em relação à dinâmica urbana existente do mercado. Seja em relação a abrigar as vivências do lugar ou pelo possível afogamento que pudesse vir a acontecer dessas vivências. Nesse ponto da reflexão, cabe esboçar um breve histórico da dinâmica desse mercado em termos da trama urbana. O mercado agia como polo aglutinador de encontros de sociabilidade. Seu pátio a céu aberto, em particular, delimitado pelas duas alas do mercado (além dos usos frequentes de encontros de descontração e intercâmbios da população local, de vendedores ambulantes, da presença dos outsiders) era um lugar de fluxo contínuo de pedestres, permitindo dessa forma a continuidade da trama urbana central. Esses usos antes da intervenção proposta não desapareceram. Se bem, tanto no edital do concurso, como na narrativa de seus ganhadores, manifestara-se o respeito à dinâmica social consolidada pelos tempos. E os arquitetos urbanistas ganhadores, após resultado vitorioso, alegaram que a cobertura idealizada deveria ser uma a mais na narrativa do mercado. Após a sua montagem, pelo tratamento dado a seu pavimento, pelos novos comércios abertos nesse espaço, os equipamentos utilizados para mobília, a delimitação entre eles quais territórios fronteiriços sutis expondo cordas, cores da mobília, marcas, preços, postura e vestimenta de seus atendentes, o conjunto dessas novidades transformou seu público frequentador. O antigo pátio aberto e público do mercado virou praça de alimentação dos shoppings centers, com movimento em todos eles e público bastante heterogêneo, mas sempre monitorado, impondo as regras do privado no que aparenta ser público.

Entre as tendências listadas pelos estudiosos em relação a mudanças contemporâneas dos mercados, fora elencada, entre outras, a sua ressignificação em termos de acobertar a tradição da vida local (Pintaudi, 2006). Em relação às características das intervenções (reunidas na família das gentrificações) que extrapolam a unidade analítica do mercado (podendo ser ruas, praças, edifícios, bairros etc., alvo das forças empresariais) num primeiro momento se evoca a ideia 
de preservação da tradição (Zukin, 2000), porém, após intervenções, impõe-se o estilo empresarial. Muda-se a paisagem local por uma global. O novo visual do antigo pátio aberto da trama urbana do centro histórico adota as roupagens da moda empresarial e expulsa a presença tradicional da diferença.

Sobre esse poder que exerce a estratégia do visual na cidade contemporânea, Castells (2014) argumenta que na reabilitação da Rua Vidal Ramos do Centro Histórico de Florianópolis, apesar da narrativa intervencionista defender a preservação de sua arquitetura tradicional, a normatização de seus equipamentos urbanos transformou a paisagem. O visual estabeleceu o novo contrato social. Na normatização da paisagem se materializa a apropriação cultural por parte dos agentes do mercado comercial. Souza (2016), por meio de uma pesquisa de fotos e cartões postais divulgadas em meio digital (internet) sobre a representação de Florianópolis em web sites, investiga as potenciais ideologias que tais elementos midiáticos carregam, como tipo de imagens da cidade propagadas na internet. No que tange ao patrimônio cultural da cidade, o autor revela que o que é veiculado pertence a uma narrativa imagética onde a maioria das pessoas é branca. E o patrimônio em si e tido "[...] como um conceito a ser vendido como um símbolo a parte da cidade e não como algo narrativo que as pessoas interagem" (Souza, 2016, p. 46). O autor reforça, por sua vez, que as imagens propagadas no meio digital destinada a sites de busca turística “[...] tentam mostrar uma cidade limpa, clara, sem tumulto, mendigos e sem interação entre as pessoas numa tentativa de higienização estética e social" (Souza, 2016, p. 46).

\section{Considerações Finais}

Em base aos diferentes relatos das práticas do cotidiano, materializadas em diversos tipos de usos, apropriações, ressonâncias, configurações e reconfigurações do centro histórico como nos exemplos citados de intervenções e pesquisas realizadas na mídia, as diversas paisagens evocadas desse cotidiano entram em dissonância com a ideia de cidade e centro histórico nos moldes da Carta de Washington (1987). Se entre os valores preservados da cidade se define seu caráter 
histórico e o conjunto de elementos materiais e espirituais que lhe determinam a imagem, cabe se perguntar como é que isso se entrelaça?

Nos primeiros exemplos apresentados da trama urbana (ladrilhos da calçada do Museu Histórico, o entorno da Catedral Metropolitana, a Escadaria do Rosário, a venda de artesanato dos indígenas nas ruas do centro) podemos entendê-los a partir da perspectiva das táticas do cotidiano de De Certeau (2008): vendedores ambulantes, moradores locais, religiosos, integrantes de movimentos sociais se expressam transformando taticamente o significado atribuído ao patrimônio construído e reconhecido.

Já nos exemplos referentes às intervenções urbanas (Aterro da Baía Sul, Rua Vidal Ramos, Mercado Público) as estratégias cunhadas por De Certeau (2008) possibilitariam melhor compreensão. E suscitam ao estudioso (Velho, 1999, p. 18) sobre a possibilidade de comunicação de diferentes tradições nessas novas intervenções submetidas a padrões socioespaciais replicados de forma exponencial. Intervenções que implicam, em algum desses casos, a segregação das partes mais caras à condição da vida que lhes dá sentido, que excluem os saberes e formas de fazer do homem comum que mantêm em pé e dão sentido às estruturas materiais (Castells, 2014).

Como sinaliza Delgadillo (2015, p. 115):

[...] na era do capitalismo neoliberal globalizado, essa herança edificada tem se transformado numa mercadoria destinada ao consumo cultural e turístico, ou numa marca para conseguir maior competitividade entre as cidades.

Para Arantes (2006, p. 431),

[...] a inserção do patrimônio no mercado reforça a compreensão de que, sendo ele um recurso material e simbólico, o balizamento de seu valor, para efeito de sua inclusão em programas sociais, de maneira geral, e de reabilitação urbana, em particular, situa-se num divisor de águas de posturas éticas e políticas. [...].

Um divisor de águas mediado pela negociação e o conflito (Velho, 2006; Arantes, 2006), pela disputa de valores, de sentidos a ele atribuídos pelos distintos agentes do campo patrimonial. E que revela até onde 
é preciso o seguimento de perto e de dentro das práticas do cotidiano (Magnani, 2002) como contribuição para a identificação dos pontos cegos para as políticas públicas patrimoniais. Nesse viés, pensar o Centro Histórico como paisagem permite questionar a ideia de permanência e expressão da tradição. Em síntese, a paisagem como categoria construída deixa de ser uma categoria estática para transformar-se e acompanhar as mudanças de seu tempo. A categoria de patrimônio sob uma perspectiva processual nos permite afirmar que a materialidade dos centros históricos (edifícios, ruas, praças, monumentos) participa também da dinâmica socioespacial - é apropriada, reconfigurada, esquecida. Ela é percebida tanto quanto texto e contexto; paisagem e moldura; passado e presente. Afasta-se de seu passado consagrado para interagir com o presente.

\section{Notas}

1 O termo gentrificação, do original gentry, refere-se aos processos de enobrecimento de áreas urbanas que, uma vez valorizadas, terminam por expulsar as populações pobres residentes no lugar. Consultar Otília Arantes (2000) e Sharon Zukin (2000) referenciadas na bibliografia.

2 O texto de José Reginaldo Santos Gonçalves Autenticidade Memória e Ideologias Nacionais: o problema dos patrimônios culturais, publicado em Antropologia dos objetos: coleções, museus e patrimônios, RJ, 2007, teve duas versões anteriores publicadas em Estudos Históricos: identidades nacionais. v. 1, n. 2, 1988, Ed. Vértice, RJ e em Fazendo Antropologia no Brasil (Organização de Esterci, N.; Fry, P.; Goldemberg, M.) DP\&A Editora/CAPES/Proin, RJ, 2001.

3 Disponível em: https://pt.wikipedia.org/wiki/Pal\%C3\%Alcio_Cruz_e_Sousa. Acessado em 19 de fevereiro de 2018.

4 A Festa do Divino Espírito Santo é uma das mais antigas e difundidas tradições do catolicismo popular brasileiro. [...] A tradição da Festa foi trazida ao Brasil pelos portugueses e aqui adquiriu características específicas e locais. [...] Os festejos duram cerca de 20 dias, em meio a alvoradas, rezas, cortejos, missas, danças e apresentações musicais de grupos tradicionais [...]. Disponível em: http://www. museuafrobrasil.org.br/pesquisa/indice-biografico/manifestacoes-culturais/festado-divino-espirito-santo. Acessado em 24 de junho de 2018

5 O movimento da Marcha das Vadias começa a partir de diversos abusos sexuais ocorridos na Universidade de Toronto, em inicio de 2011 e, em protesto às observações de um agente policial que recomendou às mulheres que "evitassem se vestir como vadias [...] para não serem vítimas". Nesse mesmo ano houve a primeira marcha também no Brasil. Disponível em: https://pt.wikipedia.org/wiki/Marcha_das_Vadias\#Brasil. Acessado em 24 de junho de 2018.

6 Obra iniciada em 1787 e concluída em 1830. A Irmandade de Nossa senhora do Rosário dos Homens Pretos era uma confraria muito pobre, composta principal- 
mente por escravos e libertos. Ver Roteiro Autoguiado do Centro Histórico de Florianópolis. Disponível em: http://www.pmf.sc.gov.br/entidades/turismo/index. php $? \mathrm{cms}=$ igreja + de + nossa + senhora + do + rosario $+\mathrm{e}+$ sao + benedito. Acessado em 24 de junho de 2018.

7 Em conversa informal com o Professor Márcio de Souza (um dos organizadores da Feira Afro-Artesanal) na escadaria do Rosário, em 5 de junho de 2018, nos foi dado o depoimento de que esse sítio fosse reconhecido como "quilombo urbano"

8 Nesse mesmo lugar, em 1925, foi construído um trapiche e, contíguo a ele, em 1928, um bar confeitaria.

9 A área do Centro Histórico, no novo Plano Diretor Municipal, em novembro de 2017 (Lei Complementar n. 482/2014), foi definida como Área de Preservação Cultural (APC) incluindo, dentro dessa categoria o patrimônio cultural arquitetônico, artístico, paisagístico, tecnológico, urbanístico dentre outros, no intuito de sua preservação, valorização e promoção desses bens.

\section{Referências}

ARANTES, A. Antonio. A guerra dos lugares: sobre fronteiras simbólicas e liminaridades no espaço urbano. In: Revista do Patrimônio Histórico e Artístico Nacional, Rio de Janeiro, v. 1, n. 23, 1994, p. 190-203.

ARANTES, Antônio. O patrimônio cultural e seus usos: a dimensão urbana. Habitus. Goiânia, v. 4, n. 1, p. 425-435, jan./jun., 2006.

ARCHDAILY. O site de arquitetura mais visitado do mundo. [2018]. Disponível em: https://www.archdaily.com.br/br/01 -159490/vencedor-doconcurso-para-a-cobertura-do-vao-central-do-mercado-. Acesso em: 27 maio 2018.

AUGÉ, Marc. Não-lugares: Introdução a uma antropologia da supermodernidade. Campinas: Papirus, 1994.

BARATTO, Romullo. Concurso para o vão central do Mercado Público de Florianópolis. 12 setembro, 2013. Disponível em: https://www. archdaily.com.br/br/01-140739/concurso-para-o-vao-central-do-mercadopublico-de-florianopolis. Acesso em: 27 maio 2018.

BARATTO, Romullo._Vencedor do concurso para a cobertura do vão central do Mercado Público de Florianópolis / Aleph Zero. 11 Dez, 2013. ArchDaily Brasil. Disponível em: https:/www.archdaily.com. br/159490/vencedor-do-concurso-para-a-cobertura-do-vao-central-domercado-publico-de-florianopolis-slash-aleph-zero. ISSN 0719-8906. Acesso em: 27 maio 2018.

BAUR, Lionel. Acervo pessoal. Vista do Palácio da esquina entre as ruas Ten. Silveira e Arcipreste Paiva Criação: 25 de maio de 2007. Disponível em: https:/pt.wikipedia.org/wiki/Palácio_Cruz_e_Sousa\#/ media/File:Florianopolis_Cruz_e_Sousa.JPG. Acesso em: 21 maio 2018. 
CANCLINI, Nestor García. Culturas híbridas: estrategias para entrar y salir de la modernidad. Nueva Edición. Buenos Aires: Paidós, 2005.

CASTELLS, Alicia N. G. La inmaterialidad del mundo de los sectores subalternos. In: LÓPEZ, José de Jesús Hernández; ROTMAN, Mónica; CASTELLS, Alicia Norma González de (org.). Patrimonio y cultura en América Latina: nuevas vinculaciones con el estado, el mercado y el turismo y sus perspectivas actuales. Guadalajara: Acento Editores/Alfredo Gutierrez R., 2010. p.75-92

CASTELLS, Alicia N. G. Revitalizações urbanas na Ilha da Magia (Florianópolis/SC). In: CASTELLS, Alicia Norma González de; SANTOS, Jeana Laura da Cunha (org.). Patrimônio Cultural e seus campos, Florianópolis: EdUFSC, 2014. p. 167-181

CASTELLS, Alicia N. G.; NARDI, Letícia (org.). Patrimônio cultural e cidade contemporânea. Coleção Urbanismo Arquitetura da Cidade. Florianópolis: Edufsc, 2012.

CLIFFORD, James. Dilemas de la cultura: Antropología, literatura y arte en la perspectiva posmoderna. Barcelona: Gedisa, 1995.

CORADINE, Lisabete. Praça XV: espaço e sociabilidade. Florianópolis: Letras contemporâneas, 1995.

CRISTIANO ESTRELA - Agência RBS. Escadaria do Rosário, no Centro de Florianópolis, recebe Feira Afro-Artesanal todas as terçasfeiras. [2017]. Disponível em: http://horadesantacatarina.clicrbs.com.br/ sc/geral/noticia/2017/07/escadaria-do-rosario-no-centro-de-florianopolisrecebe-feira-afro-artesanal-todas-as-tercas-feiras-9838696.html. Acesso em: 22 maio 2018.

DE CERTEAU, Michel. A invenção do cotidiano: artes de fazer. Petrópolis: Vozes, 2008.

DELGADILLO, Víctor. Patrimonio urbano, turismo y gentrificación. In: DELGADILLO, Víctor; SALINAS, Iban Díaz e Luis (coord.). Perspectivas del estudio de la gentrificación en México y América Latina. México: UNAM, Instituto de Geografía, 2015.

DELGADILLO, Víctor. Presentación. La disputa por los mercados (dossier). Alteridades, UAM, México, año 26, n. 51, p. 1-9, enero-junio de 2016.

FAVERO, Marco. Agencia RBS. Mercado Público de Florianópolis tem Oktoberfest. 2016. Disponível em: http://cbndiario.clicrbs.com.br/sc/ noticia-aberta/mercado-publico-de-florianopolis-tem-oktoberfest- 176580. html. Acesso em: 21 maio 2018. 
FONSECA, M. C. L. Referências culturais: base para novas políticas de Patrimônio. In: BRASIL. Patrimônio imaterial: o registro do Patrimônio Imaterial. Dossiê final das atividades da Comissão e do Grupo de Trabalho Patrimônio Imaterial. 2. ed. Brasília, DF: Ministério da Cultura, Instituto do Patrimônio Histórico e Artístico Nacional, 2003. p.83-97.

GONÇALVES, José Reginaldo Santos. Autenticidade Memória e Ideologias Nacionais: o problema dos patrimônios culturais. In: GONÇALVES, José Reginaldo Santos. Antropologia dos objetos: coleções, museus e patrimônios. Rio de Janeiro, 2007. p. 117-138.

GONÇALVES, José Reginaldo Santos. Ressonância, materialidade e subjetividade: as culturas como patrimônios. Revista Horizontes Antropológicos, PPGAS da UFRGS, Rio Grande do Sul, v. 11 n. 23, jan./ jun., 2005.

GOROSITO KRAMER, Ana María. Liderazgos Guaraníes. Argentina: Camera de Diputados de La Nacion, Sesiones Ordinarias, 2001.

LIMA FILHO, Manuel. Cidades Patrimoniais e Identidades Nacionais: questões antropológicas na perspectiva comparativa entre o Brasil e os Estados Unidos. In: LIMA FILHO, Manuel Ferreira; BEZERRA, Márcia. (org.). Os caminhos do patrimônio no Brasil. Goiânia: Alternativa, 2006. p. 17-42.

MAGNANI, J. G. C. De perto e de dentro: notas para uma etnografia urbana. Revista Brasileira Ciências Sociais, [S.l.], v. 17, n. 49, p. 11-29, 2002.

ORNATO ARQUITETURA. Catedral Metropolitana de Florianópolis. [2015]. Disponível em: http://www.ornatoarquitetura.com.br/portfolioitems/catedral-metropolitana-de-florianopolis/. Acesso em: 21 maio 2018.

PARODE, Moema, C. Cultura entrelaçada na cidade: entre a (re) existência, o reconhecimento e a legitimidade da presença indígena em Florianópolis. Dissertação (mestrado) - Universidade Federal de Santa Catarina, Centro Tecnológico, Programa de Pós-Graduação em Arquitetura e Urbanismo, Florianopolis, 2018. p.142

PETROSKI, José Maria. Família Petroski. [2018]. Disponível em: https:// familiapetroski.blogspot.com.br/2012/04/praca-fernando-machadoflorianopolis.html. Acesso em: 21 maio 2018.

PINTAUDI, Silvana Maria. Os mercados públicos: metamorfoses de um espaço na história urbana. Cidades, [S.l.], v. 3, n. 5, p. 81-100, 2006. 
PRATS, L. L. Antropología y Patrimonio. Barcelona: Ariel, 1997.

SOUZA, F. A. Fotografias vivas: análise visual da representação de Florianópolis em mídia digital. Cadernos NAUI, Florianópolis, v. 9, n. 5, p. 30-48, 2016.

VELHO, G. Patrimônio negociação e conflito. Mana Estudos de Antropologia Social, [S.l.], v. 12, n. 1, p. 237-248, 2006.

ZUKIN, S.H. Paisagens urbanas pós-modernas: mapeando cultura e poder. In: ARANTES, Antonio. (org.). O espaço da diferença. Campinas, SP: Papirus, 2000. p. 208-256.

Recebido em 03/07/2018

Aceito em 19/09/2018 